\title{
Gnomoniopsis smithogilvyi, a canker causing pathogen on Castanea sativa: First report
}

\section{Mudasir Ahmad Dar and Mahendra Rai*}

Department of Biotechnology, Sant Gadge Baba Amravati University Amravati, Maharashtra, India - 444602;

Dar MA, Rai MK 2015 - Gnomoniopsis smithogilvyi a canker causing pathogen on Castanea sativa: First report. Mycosphere 6(3), 327-336, Doi 10.5943/mycosphere/6/3/8

\begin{abstract}
In India, sweet Chestnut (Castanea sativa Mill.) is cultivated in temperate parts of Northern India. During 2009-2013, a regular survey of cankers of chestnut was made for presence of Cryphonectria and related genera. Almost $80 \%$ of orchards were infected by fungal pathogens causing cankers. The cankers formed long regular cracks in the bark which sometimes extends to xylem tissue. In the current study, Gnomoniopsis smithogilvyi was identified using morphological and phylogenetic analysis of the ITS region of ribosomal DNA. The canker formation was clearly observed on the young sprouts, stems and branches. Here, we report Gnomoniopsis smithogilvyi as canker associated fungus on chestnut trees in India. It appears that either geographic isolation or the unique growing conditions in India may have provided an effective barrier to the achievement or establishment of pathogenesis in G. smithogilvyi. Wounds caused by mechanical injuries or pruning possibly are providing routes for infection.
\end{abstract}

Keywords - Cryphonectria sp. - chestnut - cankers - India - ITS - Phylogeny

\section{Introduction}

Gnomoniopsis species are known throughout the northern hemisphere and mostly occur on dead branches and twigs attached to the plant as well as on overwintered dead leaves. Some species of this genus like Gnomoniopsis fructicola are pathogenic, cause leaf blotch and petiole blight on strawberries (Songonov et al. 2008). Similar to other members of Gnomoniaceae, species of Gnomoniopsis also exist as endophytes in healthy host plants (Rossman et al. 2007). Three species of Gnomoniopsis (G. smithogilvyi, G. castanea and G. tamietti) have been isolated from chestnut trees so far. G. castanea and G. tamietti are consistently associated with nut-rot and cause disease when artificially inoculated to fruits or flowers (Visentin et al. 2012). The species G. smithogilvyi Shuttleworth et al. is a recently described species of the genus Gnomoniopsis (Crous et al. 2012). Generally, it occurs as saprobe on dead burrs, kernels and branches of Castanea sp. and also as an endophyte in asymptomatic flowers, leaves and stems on this tree species (Shuttleworth 2012). Species of Gnomoniopsis smithogilvyi on chestnut trees were isolated as endophytes and associated with rotten chestnuts and chestnut galls in Italy (Vettraino et al. 2011), and are documented from chestnut in New Zealand (Sogonov et al. 2008).

Chestnut (Castanea sp.) trees are commercially very important for the temperate world. These trees have been cultivated for nuts and wood for thousands of years. The health condition of 
chestnut trees is continuously affected by fungi, insects, bacteria and viruses. But, among these, fungi play a key role for the destruction of this economically valuable species. The continuous loss of this vegetation from the major parts of the world indicates the stress of fungi on chestnut trees (Juhásová et al. 2011, Aumeeruddy-Thomas et al., 2012). The most important fungal pathogen is Cryphonectria parasitica, which caused lot of destruction to this vegetation throughout the globe (Anagnostakis 1987). In India, during British colonial rule in the mid 1700s to 1947, the sweet Chestnut (Castanea sativa) was widely introduced in the temperate parts, mainly in the lower to middle Himalayas like Kashmir province of Jammu and Kashmir State (Anonymous 1992, Pandit et al. 2009, 2011). These trees are continuously affected by pathogenic fungi like species of Cryphonectria and other pathogens.

Since from last many decades, Indian chestnut population has been suffering increasing losses, due to blight and cankers. The disease was initially attributed to fungi commonly found on chestnut bark, such as Cryphonectria parasitica, but a more detailed analysis revealed Gnomoniopsis smithogilvyi as one among the main causal agent of bark cankers on Indian chestnut. The present study reports, characterized the presence of $G$. smithogilvyi in India as a canker causing pathogen.

\section{Materials and Methods}

\section{Sample collection and isolation}

Samples consisting of fruiting structures from cankers were collected from 2009 to 2013; in more than eight chestnut stands located in the Kashmir valley of India. A minimum of 05 to 30 trees were sampled in every year at each stand, depending on the total number of trees in a stand and amount of disease. The cankers observed on the bark of stem were used for sampling. Samples of 5-6cm bark pieces were taken from the edge of the cankered bark, bearing fruiting structures. From these bark pieces, $6 \mathrm{~mm}$ small pieces were cut by cork-borer and were surface sterilised with 90\% alcohol for 60 seconds. These surface sterilized bark pieces were placed on to Potato Dextrose Agar (PDA) in petri plates (Downes and Ito 2001). The inoculated plates of PDA were incubated for 7-9 days at room temperature $25^{0 \pm} 2^{0} \mathrm{C}$. The colonies of the fungus were obtained within 8 days after inoculation. The cultures have been deposited in Department of Biotechnology, SGB Amravati University with accession numbers (Table 1).

\section{Morphology}

The isolates were incubated on PDA at $25^{\circ} \mathrm{C}$ for 10 days; conidiomata and conidia from each strain were measured under illuminated Carl Zeiss light microscope (Carl Zeiss, Germany) at 40X magnification. Fruiting structures were cut from the bark specimens and were observed under the microscope by macerating first in $3 \% \mathrm{KOH}$ and then transversely sectioning them, in order to identify them. Bark samples were examined for the presence of the teleomorphic stage of the fungus with a stereo-microscope. Ascomata, asci, and ascospores were measured with the light microscope. Standard deviation and length ratio were determined for both conidia and ascospores. Some ascospores were cultured on PDA at $25^{\circ} \mathrm{C}$ to produce the anamorphic stage. Measurements of asci, ascospores and conidia are reported as minimum and maximum values in parentheses, and ranges as intervals between the first and third quartile as suggested (Sogonov et al. 2008). All measurements were carried out in three replicates. Arithmetic means, standard deviations and numbers of measurements are provided in parentheses. Thus, measurements are expressed as (min) Q (-max) $\mu \mathrm{m}$.

\section{PCR Amplification and sequencing of ITS Region}

Cultures of the fungus were used for the isolation of DNA. The DNA isolation was carried out using Fungal DNA Isolation Kit provided by Chromous Biotech pvt. Ltd., Bangalore. DNA samples of the fungus were amplified for the ITS (Internal Transcribed Spacers) region using PCR. For amplification of ITS region, we used ITSEnF: (5'-AAGGATCATTACAGAGCGAGAGG-3') 
and ITSEnR: (5'-GGATGACCGGACAAAGGTG-3) as primers. The PCR reactions for ITS sequencing were carried out in a total volume of $25 \mu \mathrm{L}$. Reaction components included $2.5 \mu \mathrm{L}$ of $10 \times$ PCR buffer (Takara Bio, Inc.), $2.5 \mu \mathrm{L}$ dNTPs, $1.25 \mu \mathrm{L}$ of $10 \mu \mathrm{M}$ forward and reverse primers, 0.75 U ExTaq (Takara Bio, Inc.), and $1 \mu \mathrm{L}$ DNA template. Cycling conditions included an initial denaturation at $95^{\circ} \mathrm{C}$ for 2 min followed by 35 cycles with a denaturation step at $94.5^{\circ} \mathrm{C}$ for 1 minute, annealing at $56^{\circ} \mathrm{C}$ for 1 minute, extension at $72^{\circ} \mathrm{C}$ for 1 minute, followed by a final extension at $72^{\circ} \mathrm{C}$ for 5 minute. PCR products were purified with QIAquick spin columns (QIAGEN). All DNA fragments for ITS region were sequenced at Samved Biotech Pvt. Ltd. (Ahmadabad, India) using the Applied Biosystems Automated 3730 DNA Analyzer with Big Dye Terminator chemistry and Ampli-Taq-FS DNA Polymerase. All sequences of ITS regions obtained in this were deposited in NCBI Gene Bank with accession numbers (Table 1).

Table 1 Isolates of Gnomoniopsis smithogilvyi with Gene Bank Accession number isolated from cankers of chestnut (Castanea sativa) trees in India.

\begin{tabular}{lcc}
\hline Isolate Number & $\begin{array}{c}\text { NCBI Accession } \\
\text { Number }\end{array}$ & $\begin{array}{c}\text { Culture Collection } \\
\text { Number }\end{array}$ \\
\hline INDA1_BUD1 & KC963935 & AU/DBT301 \\
INDA2_BUD2 & KC963936 & AU/DBT302 \\
INDB1_BUD3 & KC963937 & AU/DBT303 \\
INDB2_BUD4 & KC963938 & AU/DBT305 \\
INDC(A)BUD5 & KC963939 & AU/DBT321 \\
INDC(R)BUD6 & KC963940 & AU/DBT306 \\
INDD(1)BUD7 & KC963941 & AU/DBT310 \\
INDE(1)BUD8 & KC963942 & AU/DBT296 \\
INDE(2)BUD9 & KC963943 & AU/DBT295 \\
INDF(2)BUD11 & KC963944 & AU/DBT294 \\
INDH(1)BUD12 & KC963945 & AU/DBT307 \\
INDH(2)BUD13 & KC963946 & AU/DBT308 \\
INDJ(1)BUD16 & KC963947 & AU/DBT297 \\
INDJ(2)BUD17 & KC963948 & AU/DBT299 \\
INDA(Hub3)A & JQ268071 & AU/DBT005 \\
INDB(Hub2)A & JQ268072 & AU/DBT006 \\
INDC(BSF5)A & JQ268073 & AU/DBT007 \\
INDD(BSF8)A & JQ268074 & AU/DBT008 \\
INDF(Hub5)A & JQ268075 & AU/DBT002 \\
INDH(BSF6)A & JQ268076 & AU/DBT011 \\
INDJ1(Cryp1)A & JQ268077 & AU/DBT013 \\
INDJ2(Cryp2)A & JQ268077 & AU/DBT012 \\
\hline
\end{tabular}

\section{Pathogencity trial on excised sprout stems}

For this trial chestnut sprout stems were harvested from a local commercial orchard. Stems were cut and cut ends were dipped in wax. Gnomoniopsis smithogilvyi isolates were selected and were used for pathogencity on chestnut stems, as they were already reported and identified as a saprobe on dead burrs and branches of Castanea sp. (Fagaceae), and is isolated from rotten chestnut kernels, or as an endophyte from asymptomatic flowers, leaves and stems (Shuttleworth 2012). For the Koch's postulation, young sprout stem were surface-sterilized with $2 \%$ sodium hypoclorite, wounded at middle with a sterile cork borer $(6 \mathrm{~mm})$ and inoculated by a mycelial plug [INDH (BSF6)] isolate was used for inoculums). The inoculums were protected by moistened cotton and sealed with paraffin film. The controls were inoculated as above with sterile water. Inoculations were carried out in November 2013 three plants per isolate. In January 2014 the fungus was tentatively re-isolated from the developed branches. To do so, lesions were surface-sterilized, cut into transverse disks and plated on PDA. Koch's postulates were fulfilled by re-isolating the same fungal isolate from the lesions that were used for inoculation. Identity of each isolate was confirmed by culture and spore characteristics. 


\section{Results}

\section{Isolation and Morphological Identification}

The agar water mycelium plugs were incubated for 7 days at temperature $25^{0} \pm 2^{0} \mathrm{C}$ on fresh PDA containing plates. The colonies of the fungus were obtained within 8 days after inoculation. One mycelial plug from each sample was transferred to fresh plates containing PDA medium for isolation of pure cultures. In this study 27 isolates were studied for their cultural morphology and molecular characteristics. The cultural morphology of these isolates was studied on the PDA medium. Colonies of isolates showed moderate to fast growth, producing slimy conidial creamy mass drops on the surface of the plate which is a characteristic feature of Gnomoniopsis species (Sogonov et al., 2008). The colonies were regular in outline with a clear and thinner margin (Fig.2AB). The mycelia of Gnomoniopsis smithogilvyi were flat and transparent, woolly or sticking to surface and dense. The margins of colonies are diffused to regular and colonies were developed in concentric circles particularly on PDA. The color varies from creamy to grey or hair- brown. Reverse colors similar to surface of the plate. The slimy conidial droplets are present at surface of the mycelia. Conidiomata produced in cultures are abundant with range of colors, black to brownish grey and conidiomata are globose to sub-globose in shape which are both erumpent and immersed in media oozing conidia of varying colors (Fig.2CD).

The perithecia of Gnomoniopsis smithogilvyi were abundantly present, devoid of stroma, semi or fully immersed in host tissue (Fig. 3A), solitary or present in groups, black in color, globose to subglobose in shape (Fig.3B). The size of perithecia were (101.5-) $238.7(-409.5) \mu \mathrm{m}$ high, (96.5-)242(-410.5) $\mu \mathrm{m}$ in diameter (solitary neck, central, straight or curved, sometimes flexuous, shorter or longer than perithecial diameter, apex sometimes translucent, necks sometimes absent). Asci are hyaline, unitunicate, obovoid to cylindrical in shape, with size between (20.5-) 31(-37.5) $\mu \mathrm{m}$ long, (4-) 5(-6.5) $\mu \mathrm{m}$ diam, with visible apical ring, containing eight, biseriate ascospores (Fig. 3C). Ascospores hyaline, 1-septate, pyriform, straight or slightly curved, ends rounded, broader at distal end, (4-)7(-12) $\mu \mathrm{m}$ long, (1-)2(-3) $\mu \mathrm{m}$ diam, length-to-width ratio, medianly 1-septate, constricted at septum; distal cell with 2-multiple guttules, and basal cell with 1 to multiple guttules, appendages absent (Fig. 3D). Germinating ascospores produced the anamorph in culture. The measurements of conidiomata were calculated (89.3-) 203.5(-490.5) $\mu \mathrm{m}$ high and (72.5-) 217.5 (-471) $\mu \mathrm{m}$ wide with pale-orange or colorless conidia (Fig. 3.9A). Conidophore, multicellular, branched, hyaline, size ranging (6.7-) $12.5(-20.5)$, bearing conidia a tip of branches.Conidia hyaline, oval, obovoid, fusoid, pyriform, straight or curved, allantoid, multiguttulate, without appendages, with size (5.7-) 7.5(-8.9) $\mu \mathrm{m}$ long, (2-) 3(-4) $\mu \mathrm{m}$ wide (Fig.3E).

Table 2 Disease incidence on chestnut nut samples collected in 2009-2013 in the Jammu and Kashmir area (Northern India). Percentage of trees infected by Gnomoniopsis smithogilvyi are given as a mean of percentage values obtained from chestnut stands in the area and samples were randomly collected, \pm standard deviation.

\begin{tabular}{llllll}
\hline Year & $\mathbf{2 0 0 9}$ & $\mathbf{2 0 1 0}$ & $\mathbf{2 0 1 1}$ & $\mathbf{2 0 1 2}$ & $\mathbf{2 0 1 3}$ \\
\cline { 2 - 3 } Mean \pm SD & $32.8 \pm 5.9 \%$ & $35.2 \pm 8.7 \%$ & $35.0 \pm 5.2 \%$ & $38.7 \pm 9.4 \%$ & $57.6 \pm 9.4 \%$ \\
\hline
\end{tabular}

\pm Standard deviation

\section{Molecular identification (DNA amplification and sequencing) and phylogeny}

Results obtained from the partition homogeneity test showed that the data for each gene region were significantly congruent $(\mathrm{p}$-value $=0.05$ ). The evolutionary history was inferred using the Maximum Likelihood method. Five most parsimonious trees were generated with similar branch lengths and topology and one was chosen for presentation (Fig.1). The overall mean distance is 0.736 among the species. This tree has a consistency index (CI) of 0.747 and retention index (RI) of 0.922. The maximum Log likelihood for this computation was -1029.361 . The substitution patterns are homogeneous among lineages, the compositional distance correlate with the number of differences between sequences. 
Table 3 Measurement of fruiting and reproductive structures with type reference for comparison

\begin{tabular}{lll}
\hline $\begin{array}{l}\text { Reproductive and fruiting } \\
\text { Structures }\end{array}$ & $\begin{array}{l}\text { Size of Reproductive and fruiting } \\
\text { structures }((\mathbf{m i n}-) \mathbf{Q}(-\mathbf{m a x}) \boldsymbol{\mu m})\end{array}$ & Type Reference for comparison \\
\hline Perithecia & $(101.5-) 238.7(-409.5) \mu \mathrm{m}$ high, & \\
& $(96.5-) 242(-410.5) \mu \mathrm{m}$ diameter & \\
Asci & $(20.5-) 31(-37.5) \mu \mathrm{m}$ long, & \\
& $(4-) 5(-6.5) \mu \mathrm{m}$ diameter \\
Ascospore & $(4-) 7(-12) \mu \mathrm{m}$ long, & Shuttleworth et al. 2012 \\
& $(1-) 2(-3) \mu \mathrm{m}$ diameter & \\
Conidiomata & $(89.3-) 203.5(-490.5) \mu \mathrm{m}$ high, \\
& $(72.5-) 217.5(-471) \mu \mathrm{m}$ wide & \\
Conidiophore & $(6.7-) 12.5(-20.5) \mu \mathrm{m}$ long & \\
Conidia & $(5.7-) 7.5(-8.9) \mu \mathrm{m}$ long, & \\
& $(2-) 3(-4) \mu \mathrm{m}$ wide & \\
\hline
\end{tabular}

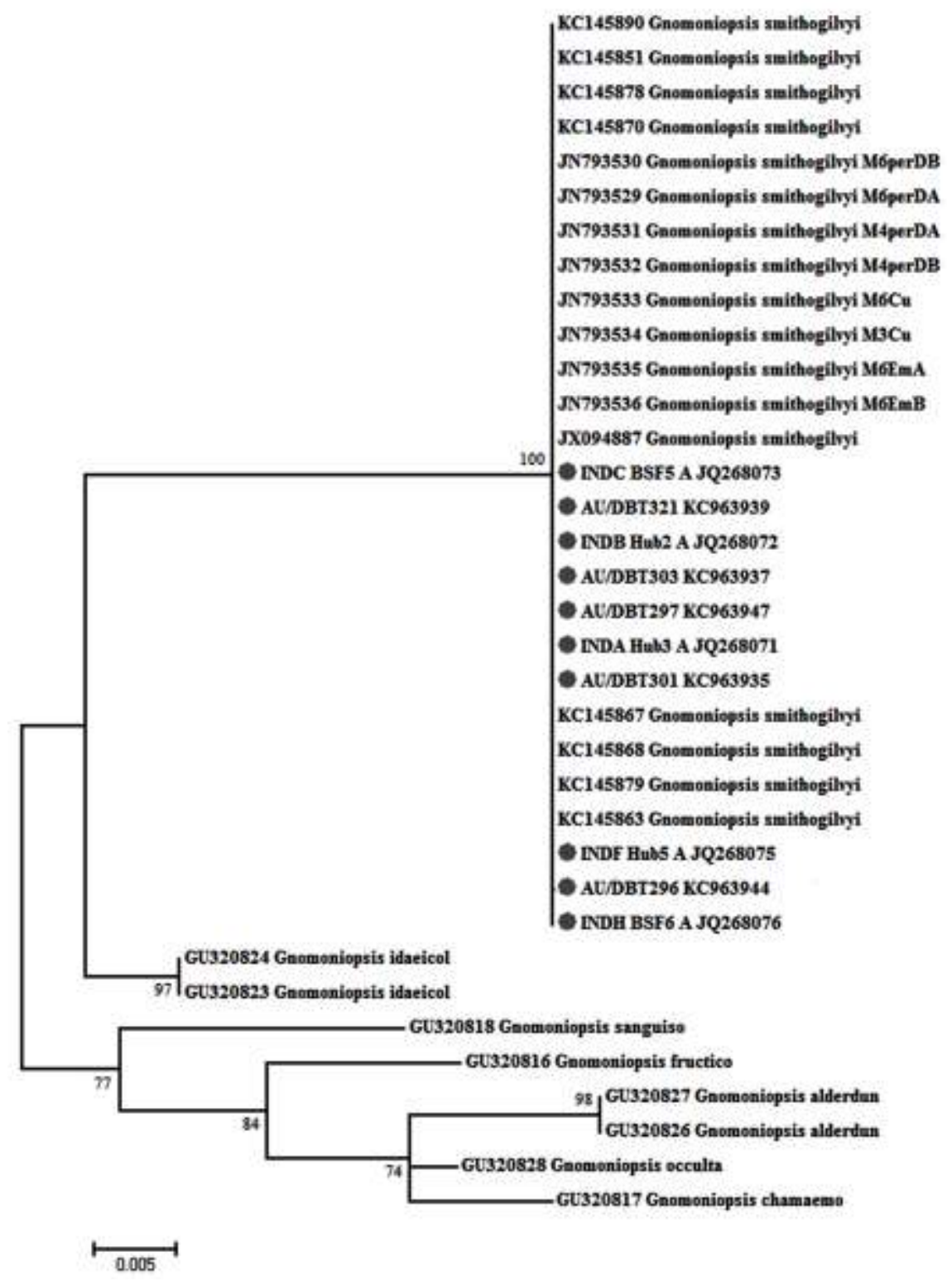

Fig. 1 - Maximum Likelihood (ML) phylogenetic analysis (ML score =-ln L scores of 1907.654) of ITS sequences of Gnomoniopsis smithogilvyi (represented by gray dots) on Castanea sp. in India with reference taxa from genus Gnomoniopsis (NCBI Accession number given at each isolate). The bootstrap values $(\geq 74 \%)$ are displayed at each branch. 

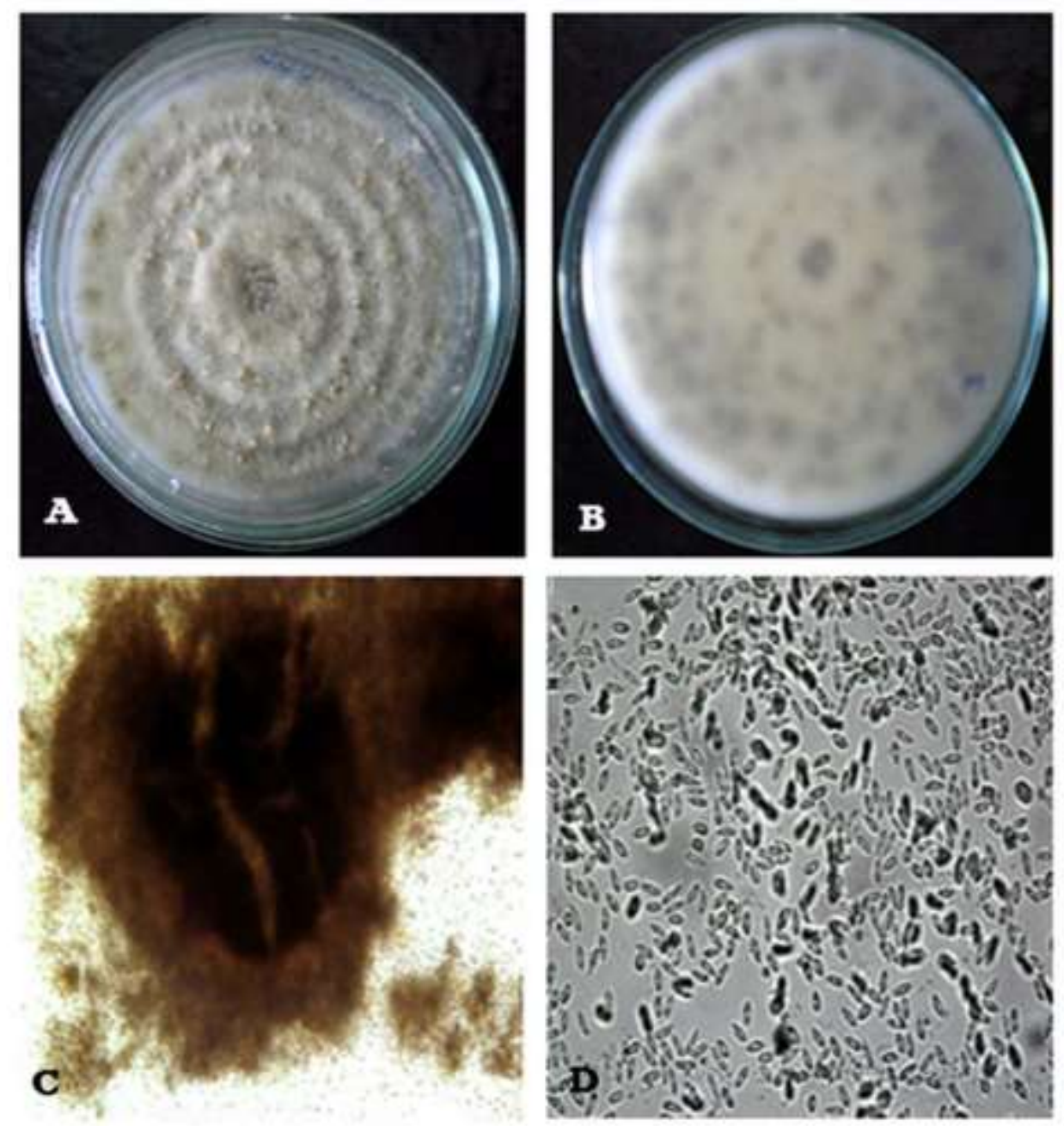

Fig. 2 A - D - Gnomoniopsis smithogilvyi culture characters A. Ventral B. Dorsal side of Plate C. Pycnidium D. Conidia

The phylogenetic analysis was carried out based on the sequence of the ITS region. Corresponding phylogenetic tree were generated with sequences from the different strains obtained in this study together with those of other Gnomoniopsis species from database. The trees obtained by neighbor-joining analysis are shown in Fig. 1 for the ITS region. BLAST comparison of the sequences gave very high similarity ( $>97 \%$ ) within each set. For each locus, the closest sequences were those from G. smithogilvyi formed common single clad (Fig. 1). G. smithogilvyi isolates from Australia, New Zealand and Italy shared maximum identity with Indian isolates. The other sequences used in the study were from G. idaeicol, G. sanguiso, G. fructico, G. alderdum, G. occulta and G. chamaemo.

Isolate sequences representing species of Gnomoniopsis from NCBI database and the sample sequences formed similar and well-supported clades reflecting the similar genera. The fungal isolates from Indian chestnut represented by round grouped along with the isolates from New Zealand and Italy, specifically formed separate clad from isolates of America. However, within a clade, unidentified isolates formed separate sub-clade linked to different clades. These were based on constant single base pair differences between isolates from the different genera (Fig.1). Similarities were most pronounced between the isolate sequences from India and those obtained from NCBI gene bank, suggesting these isolates from India represents Gnomoniopsis species. 


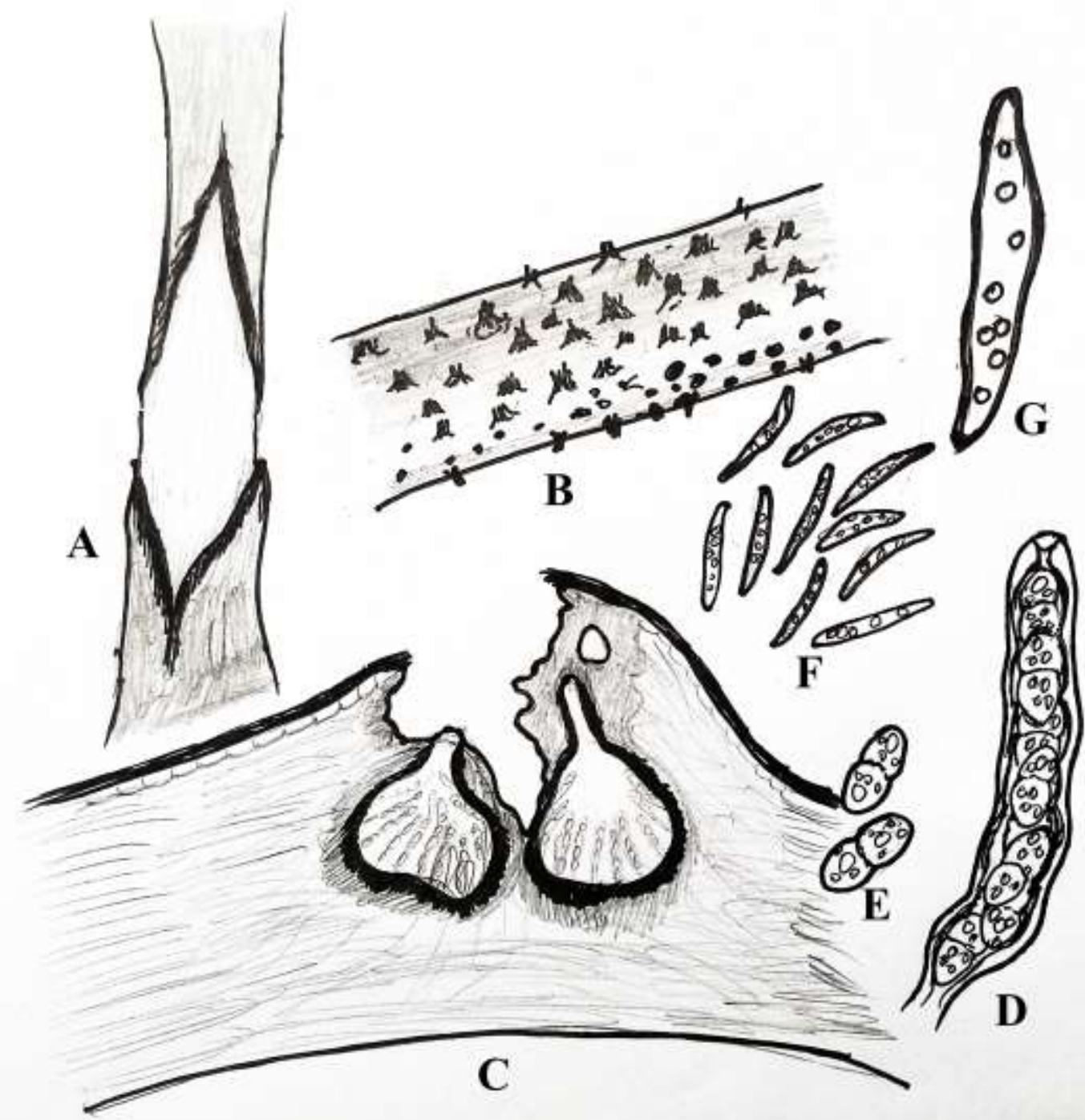

Fig. 3 A - G - Photographs showing Gnomoniopsis smithogilvyi A. Cankered Stem of chestnut B. Branch of an infected chestnut C. T.S. of Perithecia D. Ascus with Ascospores and Apical Ring E. Guttulated Ascospores F. Conidia G. Enlarged view of guttulated conidium

\section{Disease incidence and Frequency of isolation}

Isolations of the fungi from the cankers of chestnut gave an overall mean of about $39 \%$ for isolates of G. smithogilvyi. This frequency was determined using samples for isolation, collected from various chestnut stands. The other fungi yielded as canker causing pathogen were majorly belonging to Cryphonectria, while other colonies of Diplodia and Cytospora (Valsa=Teleomorph) species developed from some samples. In the subsequent years, the existing fungus G. smithogilvyi was consistently isolated with a mean frequency ranging from $32.0 \%$ (2009) to $58.0 \%$ (2013) (Table 2).

\section{Pathogencity Trials}

Once inoculated, colonization of tissues by the G. smithogilvyi isolates resulted in lesions that were evident as a considerable darkening of the stem (Fig. 4AB). These lesions extended along the phloem and became more prominent as the epidermal layers were scraped away. All isolates produced lesions significantly different from the control (Fig.4C). Symptom development following inoculation; according Koch's postulate proved the pathogencity of G. smithogilvyi isolates on chestnut stem. 


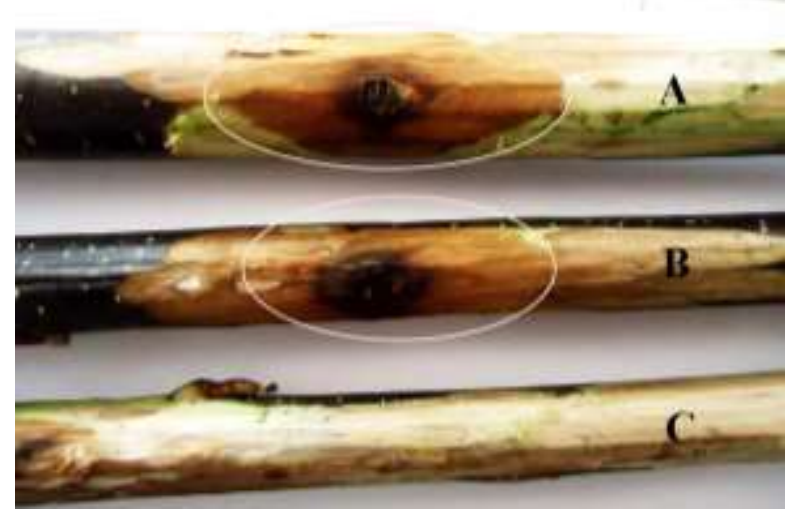

Fig. 4 A - C - Photograph showing Koch's postulation A \& B. Lesions on sprout after inoculation of 9 (A) and 11 (B) days respectively, inoculated with Gnomoniopsis smithogilvyi isolate mycelial plugs C. Control, inoculated with sterile distilled water.

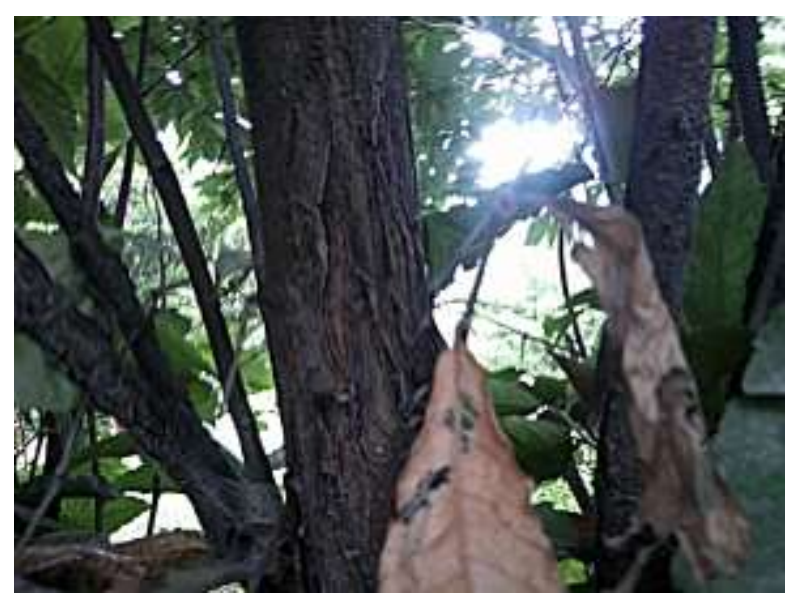

Fig. 5 - Photographs showing juvenile Cankered Stems of chestnut trees, the cankers were usually observed on crown of stem.

\section{Discussion}

India is known for a diversity of tropical and temperate trees. Chestnut is an important tree of the country known for its wood and nuts (Pandit et al. 2009). The main pathogenic fungi, causing cankers in chestnut trees are normally Cryphonectria parasitica at major parts of the world (Anagnostakis 1987). A fascinating result of this study was that the chestnut population was not only infected by Cryphonectria species, but was infected by other fungi not known as pathogen in earlier records. These results were unexpected as the fungus is known to be saprobe on and associated with rotten branches and burs of chestnut trees (Crous et al. 2012). The isolates of $G$. smithogilvyi used in the present study were obtained from cankers of chestnut sprouts and branches, and were studied for further investigation (Fig. 5). The identification of the fungi was based on morphology and molecular markers like Internal Transcribed Spacers (ITS). The ITS sequence based phylogenetic study of isolates showed homology with $100 \%$ bootstrap value to isolates from Italy, New Zealand and Australia (Fig.1). The isolates represented by light gray dots are the representative isolates from India and are sharing common clad with isolates of G. smithogilvyi from Italy, New Zealand and Australia described by Shuttleworth et al. (2012). Also the morphological (Table 3) and cultural characters described in this study are similar to $G$. smithogilvyi (Shuttleworth et al. 2012). The shape and color of fruiting structures were similar to the morphological characters illustrated for G. smithogilvyi Shut. Liew \& Guest. The black color perithecia devoid of stromata, ascus with an apical ring, guttulated conidia and ascospores and slimy conidial droplets on culture are the characters observable in Indian isolates, which are similar to those of G. smithogilvyi described earlier (Shuttleworth et al. 2012). 
The pathogencity test using Koch's postulation has shown that G. smithogilvyi is associated with cankers of stem and can also produce lesions on chestnut trees. We have demonstrated that $G$. smithogilvyi in the native vegetation of chestnut are able to cause disease. This fungal species may pose an economic risk to the chestnut population in other chestnut harboring countries too.

Gnomoniopsis smithogilvyi are usually reported with rotten branches and burs, considered as saprophyte and were not associated with cankers or any pathogenesis. In this study, these unique fungi were isolated from canker during survey of Cryphonectria sp. on chestnut in India. This difference in fungal behavior may have aroused due to variable physical, biological and environmental conditions. This is the first report of presence of G. smithogilvyi in India and also responsible for cankers which are developed at the base of the juvenile sprouts and stem and aerial branches of mature trees.

\section{Acknowledgements}

Mudasir Dar is thankful to Engineering and Technology UGC, New Delhi for providing fellowship to complete this research project. We are also thankful to Cécile ROBIN, INRA, UMR1202 BioGeCo, 69, Route d'Arcachon, 33612 Cestas Cedex, France, for her help in the sequencing of some samples. Our thanks also goes to Dr. Lucas Shuttleworth, Botanic Gardens Trust, Plant Pathology, The University of Sydney, Australia, for analysing the sequences and to Dr. Vaibhav Tiwari, Department of Biotechnology, Sant Gadge Baba Amravati University, Amravati $(\mathrm{MH})$, India, for his help in molecular studies and experimentation.

\section{References}

Anagnostakis SL. 1987 - Chestnut blight: The classical problem of an introduced pathogen. Mycologia 79, 23-37

Anonymous. 1992 - The wealth of India. Raw materials, Vol. II, p. 374-375. CSIR, New Delhi

Aumeeruddy-Thomas Y, Therville C, Lemarchand C, Lauriac A, Richard F. 2012 - Resilience of Sweet Chestnut and Truffle Holm-Oak Rural Forests in Languedoc-Roussillon, France: Roles of Social-Ecological Legacies, Domestication, and Innovations. Ecology and Society, $17,1-12$

Crous PW, Summerell BA, Shivas RG, Burgess TI, Decock CA, et al. 2012 - Fungal Description sheet, Gnomoniopsis smithogilvyi L.A. Shuttleworth, E.C.Y. Liew \& D.I. Guest, sp. nov. Persoonia. 28, 138-182.

Downes FP, Ito K (2001). Compendium of methods for the microbiological examination of foods. 4th ed., Am. Public Health Assoc. Press, Washington, DC, USA.

Juhásová G, Adamcíková K, Robin C. 2011 - Results of biological control of chestnut blight in Slovakia. Phytoprotection, 86,19-23

Pandit AH, Kour A, Wani MS, Mir MA, 2009 - Genetic resources of chestnut in Kashmir Valley. Proc. Intl. Workshop on Chestnut Management in Mediterranean Countries. Acta Hort. 815, 51-56.

Pandit AH, Mir MA, Kour A, Bhat KM. (2011) Selection of Chestnuts (Castanea sativa) in Srinagar District of the Kashmir Valley, India. International Journal of Fruit Science. 11, 111-118.

Rossman AY, Farr DF, Castlebury LA. 2007 - A review of the phylogeny and biology of the Diaporthales. Mycoscience 48, 135-144

Shuttleworth L, Guest DI, Liew ECY. 2012 - Gnomoniopsis smithogilvyi L.A. Shuttleworth, E.C.Y. Liew \& D.I. Guest, sp. nov. Fungal Planet description sheets: 107-127. Persoonia 28: $138-182$

Shuttleworth LA. 2012 - The biology and management of chestnut rot in southeastern Australia. $\mathrm{PhD}$. thesis. Faculty of Agriculture and Environment. The University of Sydney, Australia.

Sogonov MV, Castlebury LA, Rossman AY, Mejía LC, White JF. 2008 - Leaf-inhabiting genera of the Gnomoniaceae, Diaporthales. Studies in Mycology 62, 1-77. 
Vettraino AM, Aleandri MP, Martignoni D, Bruni N, Vannini A. 2011 - Endophytism of Gnomoniopsis sp. in chestnut tissues. Department of Innovation in Biological, Agro-food and Forest Systems, University of Tuscia, Viterbo, Italy.

Visentin I, Gentile S, Valentino D, Gonthier P, Tamietti G, Cardinale F. 2012 - Gnomoniopsis castanea sp. Nov. (Gnomoniaceae, Diaporthales) as the causal agent of nut rot in sweet chestnut. Journal of Plant Pathology. 94, 411-419. 